\title{
Platelet-Activating Factor-Acetylhydrolase Gene (PLA2G7) Expression in Children with a History of Food Anaphylaxis
}

Natalia Vladislavovna Esakova', Ekaterina Karenovna Saakyan², Natalia Sergeevna Kondratieva ${ }^{2}$, Zarema Grigorievna Kokaeva ${ }^{2}$, Anastasia Petrovna Nesterova $^{3}$, Pavel Kirillovich Golovatenko-Abramov ${ }^{3}$, Eugene Alexandrovich Klimov ${ }^{2,}$, Marina SergeevnaTreneva' and Alexander Nikolaevich Pampura ${ }^{1 *}$

'Allergy and Clinical Immunology Department, Research and Clinical Institute for Pediatrics at the Pirogov Russian National Research Medical University, Moscow, Russia

${ }^{2}$ Department of Genetics, Faculty of Biology, Lomonosov Moscow State University, Moscow, Russia

${ }^{3}$ University diagnostic Laboratory, Ltd, Moscow, Russia

"Corresponding author: Pampura AN, Allergy and Clinical Immunology Department Head, Research and Clinical Institute for Pediatrics at the Pirogov Russian National Research Medical University, Taldomskaya str. 2, Moscow, Russia 125412, Tel: (+7495) 484-45-57; E-mail: apampura@pedklin.ru

Received date: March 27, 2015; Accepted date: May 21, 2015; Published date: May 31, 2015

Copyright: ( 2015 Pampura AN, et al. This is an open-access article distributed under the terms of the Creative Commons Attribution License, which permits unrestricted use, distribution, and reproduction in any medium, provided the original author and source are credited.

\begin{abstract}
Background: One of key functions in the pathogenesis of anaphylaxis is held by platelet-activating factor (PAF). However, no research on detection of transcriptional activity of PAF-acetylhydrolase gene (PLA2G7) in patients with anaphylaxis has been held so far.
\end{abstract}

The aim of this study is to evaluate transcriptional activity (expression at mRNA level) of PLA2G7 gene (plateletactivating factor acetylhydrolase) in patients with a history of anaphylaxis.

Methods: 97 children were enrolled in the study: 27 children with a history of food anaphylaxis (group 1); 35 children with atopic dermatitis (group 2); 35 children without allergic diseases (group 3). Group 3 children were tested with Phadiatop and Phadiatop Infant ("Phadia 100"; "Phadia AB", Sweden): 26 children were IgE-negative, 9 children were IgE-positive.

RNA was extracted from blood samples with Trizol RNA Prep kits ("Isogen”, Russia). cDNA production was performed with MMLV RT kit ("Evrogen", Russia). Real-time PCR was held with CFX-96 device ("Bio-Rad", USA) and qPCRmix-HS PCR mix ("Evrogen", Russia). Oligonucleotide primers and probes were synthesized at "DNKSintez" (Russia).

Results: In children with a history of food anaphylaxis statistically significant decrease in PLA2G7 gene expression was detected $(p<0.05)$ in compare with children free of allergic diseases.

Transcriptional activity of PLA2G7 was significantly lower in children with severe anaphylaxis and in children with moderate anaphylaxis in compare with mild anaphylaxis children $(p<0.05)$. In moderate/severe anaphylaxis children PLA2G7 expression was more than three times decreased in compare with atopic dermatitis children $(p<0.05)$.

In children with anaphylaxis characterized by clinical symptoms of cardiovascular manifestations the PLA2G7 expression level was significantly reduced in compare with anaphylaxis children free of cardiovascular symptoms $(p<0.05)$.

Conclusion: Reduction of blood cells PLA2G7 mRNA level in children with a history of food anaphylaxis may be considered to be a biomarker of severe anaphylaxis.

Keywords: Anaphylaxis; Food allergy; PAF-acetylhydrolase; Gene transcriptional activity; Platelet-activating factor

\section{Introduction}

Anaphylaxis is an acute life threatening allergic reaction that may lead to death [1]. Mechanisms underlie anaphylaxis pathogenesis have not been studied completely. Multiple research data give the evidence that the range of immune cells and mediators involved in anaphylactic reaction is more complex than originally supposed. One of the key functions in anaphylaxis pathogenesis is held by platelet-activating factor (PAF, 1-o-alkyl-2-acetyl-sn-glycero-3-phosphocholine) [2-4].
The latter is a pro-inflammatory phospholipid synthesized and secreted by mast cells, monocytes and tissue macrophages [5]. PAF is one of the main intercellular interactions regulators along with prostaglandins, leukotriens, tumor necrosis factor, interleukins, histamine, serotonin, etc. [6]. PAF receptor binding is resulted by development of various diseases multiple symptoms, including allergic reactions [7]. In animal models (rabbit, mouse) PAF is capable for various manifestations of anaphylactic reactions (hypotension, edema, bronchial constriction etc.) [7-9]. High levels of circulating PAF have been found both in vitro [6] and in vivo in sensitized mice after antigenic stimulation, as well as in patients with anaphylaxis [3,10-12]. Blood serum PAF and PAF-acetylhydrolase levels correlate with 
Citation: Esakova NV , Saakyan EK, Kondratieva NS, Kokaeva ZG, Nesterova AP, Golovatenko-Abramov PK, Klimov EA, Treneva MS, Pampura AN (2015) Platelet-Activating Factor-Acetylhydrolase Gene (PLA2G7) Expression in Children with a History of Food Anaphylaxis. J Allergy Ther 6: 211. doi:10.4172/2155-6121.1000211

Page 2 of 5

severity of anaphylactic reactions in patients $[11,12]$. Inhibition of PAF receptors binding reduces the intensity of severe symptoms in anaphylaxis $[13,14]$.

Considering the evident role of PAF and PAF-acetylhydrolase in anaphylaxis development, we suggest that PAF-acetylhydrolase (PLA2G7) gene expression reduction may be active in patients with anaphylaxis history and act as its biomarker.

\section{Methods}

\section{Design of the study}

The study was held at the Allergy and Clinical Immunology Department of Clinical Research Institute of Pediatrics, within 2011-2013 years.

97 children were enrolled in the study: 27 children ( 16 boys and 11 girls) aged from 8 months to 15 years $(\mathrm{Me}=6$ years [Q1=3; $\mathrm{Q} 3=11])$ with a history of food anaphylaxis (group 1); 35 children (23 boys and 12 girls) aged from 5 months to 17 years $(\mathrm{Me}=5$ years [Q1=4; Q3=9]) with atopic dermatitis (group 2); 35 children ( 18 boys and 17girls) aged from 2 to 17 years $(\mathrm{Me}=5$ years [Q1=4; Q3=7]) without allergic diseases (group 3). Group 3 children were tested with Phadiatop or ImmunoCap 100 (Phadia $\mathrm{AB}$, Sweden) to evaluate blood serum specific IgE concentrations; 26 children were IgE-negative, 9 children were IgE-positive.

Anaphylaxis was diagnosed retrospectively with clinical diagnostic criteria of European Academy of Allergy and Clinical Immunology consensus document [15]. Anaphylaxis was considered mild, moderate or severe in accordance with standard severity criteria [15]. Atopic dermatitis severity was evaluated with SCORAD scale [16].

The study was approved by Local Ethics Board at Moscow Research Institute of Pediatrics and Child Surgery by Russia Ministry of Health and Social Welfare (protocol \#42/13) and meets The Helsinki Accords principles. Informed consent had been obtained from all patients or their parents/guardians.

\section{Detection of PLA2G7 gene expression}

Transcriptional activity (mRNA level) of PLA2G7 gene was evaluated in patients' whole blood samples. Anaphylaxis children blood samples were obtained outside the anaphylactic reaction. RNA extraction from blood samples was carried out with Trizol RNA Prep kits ("Isogen", Russia). cDNA production was performed with MMLV RT kit ("Evrogen", Russia). Oligonucleotide primers and PLA2G7 gene cDNA probe were designed for the study and synthesized by "DNK-Sintez" (Russia): F: GGACAAGTCTTGGCTCTACCTTA; R: TGCTCTTTGCCGTACCTGC; probe: FAMACCCTGAAACAAGAGGAGGAGACACAT-BHQ1. A housekeeping gene GAPDH was used as a reference; primers and probes designed and synthesized by "DNK-Sintez" (Russia). Standards for real-time PCR were prepared by amplification of PCR products in pal-TA plasmid ("Evrogen", Russia). Extracted and purified plasmid was diluted 100, 1000, and 10000 times. Real-time PCR was carried out with CFX-96 thermal cycler ("Bio-Rad", USA) and real-time PCR kit qPCRmix-HS ("Evrogen", Russia). Both genes PCR conditions were: $94^{\circ} \mathrm{C}(3 \mathrm{~min}), 45$ cycles: $94^{\circ} \mathrm{C}(20 \mathrm{sec}), 60 \mathrm{oC}(15 \mathrm{sec}), 72^{\circ} \mathrm{C}(30 \mathrm{sec})$. The real-time PCR was three replicates for each cDNA sample. The calculations used the mean value CT.

\section{Statistical analysis of the data}

The mean values CT difference in the triplicate samples against the reference gene was calculated with Excel (Microsoft Office 2010) to get the $\Delta \mathrm{CT}$. The relative quantitative value was then expressed as $2-\Delta \mathrm{CT}$ using the comparative CT method. Statistical analysis for $2-\Delta \mathrm{CT}$ data was carried out with median, upper quartile and lower quartile calculation. Fisher test and Mann Whitney U-test were used to evaluate non-parametric variables. STATISTICA 8.0 software package was used for data analysis. The level of statistical significance was set at $\mathrm{p}<0.05$.

\section{Results}

\section{Analysis of PLA2G7 transcriptional activity}

PLA2G7 gene mRNA level was assessed in blood cell samples of all children recruited in the study.

The significant decrease of PLA2G7 gene expression was found in anaphylaxis children $(\mathrm{Me}=0.045[\mathrm{Q} 1=0.001 ; \mathrm{Q} 3=0.193])$ in compare with Ig-E-negative children $(\mathrm{Me}=0.127$ [Q1=0.033; $\mathrm{Q} 3=1.71])$ and in compare with Ig-E-positive children ( $\mathrm{Me}=6.9$ [Q1=0.6; Q3=17]) $(\mathrm{p}<0.05)$.

In atopic dermatitis children PLA2G7 gene expression decrease was observed $(\mathrm{Me}=0.018[\mathrm{Q} 1=0.004 ; \mathrm{Q} 3=0.116])$ in compare with children without allergic diseases $(\mathrm{p}<0.05)$.

No significant difference in transcriptional activity was observed between children with anaphylaxis and children with atopic dermatitis $(\mathrm{p}>0.05)$.

PLA2G7 high expression in Ig-E-positive children in compare with Ig-E-negative children $(\mathrm{p}<0.05)$ was in focus.

Transcriptional activity of PLA2G7 was significantly lower in children with severe anaphylaxis $(\mathrm{n}=8) \quad(\mathrm{Me}=0.001 \quad[\mathrm{Q} 1=0.0002$; $\mathrm{Q} 3=0.004])$ and in children with moderate anaphylaxis $(\mathrm{N}=10)$ $(\mathrm{Me}=0.03[\mathrm{Q} 1=0.005 ; \mathrm{Q} 3=0.08])$ in compare with mild anaphylaxis children $(\mathrm{N}=9)(\mathrm{Me}=0.19$ [Q1=0.16; $\mathrm{Q} 3=0.38])(\mathrm{P}<0.05)$. (Figure 1) It should be noted that asthma in moderate/severe anaphylaxis children was diagnosed more often in compare with mild anaphylaxis children ( $67 \%$ vs. $13 \%$ respectively, $\mathrm{p}<0.05)$. In atopic dermatitis children asthma was diagnosed in $40 \%$ of patients and allergic rhinitis was diagnosed in $63 \%$ of children.

In atopic dermatitis children no correlation between the severity of atopic dermatitis (according to SCORAD scale) and the level of PLA2G7 gene transcriptional activity was found. PLA2G7 gene expression level in patients with severe anaphylaxis was significantly reduced in compare with mild atopic dermatitis children $(n=6)$ $(\mathrm{Me}=0.54[\mathrm{Q} 1=0.03 ; \mathrm{Q} 3=19.7])$ and moderate/severe atopic dermatitis children $(\mathrm{n}=29)(\mathrm{Me}=0.02[\mathrm{Q} 1=0.004 ; \mathrm{Q} 3=0.08])(\mathrm{p}<0.05)$.

The correlation between PLA2G7 gene transcriptional activity and clinical manifestations of anaphylaxis was evaluated. In children $(n=6)$ with cardiovascular (hypotension, tachycardia/brachycardia) manifestations mentioned in anaphylaxis episode the level of PLA2G7 gene expression was significantly reduced $(\mathrm{Me}=0.001[\mathrm{Q} 1=0.000001$; Q3 =0.005]) in compare with children free of cardiovascular manifestations $(\mathrm{n}=21) \quad(\mathrm{Me}=0.01 \quad[\mathrm{Q} 1=0.006 ; \mathrm{Q} 3=0.3]) \quad(\mathrm{p}<0.05)$. (Figure 2). 


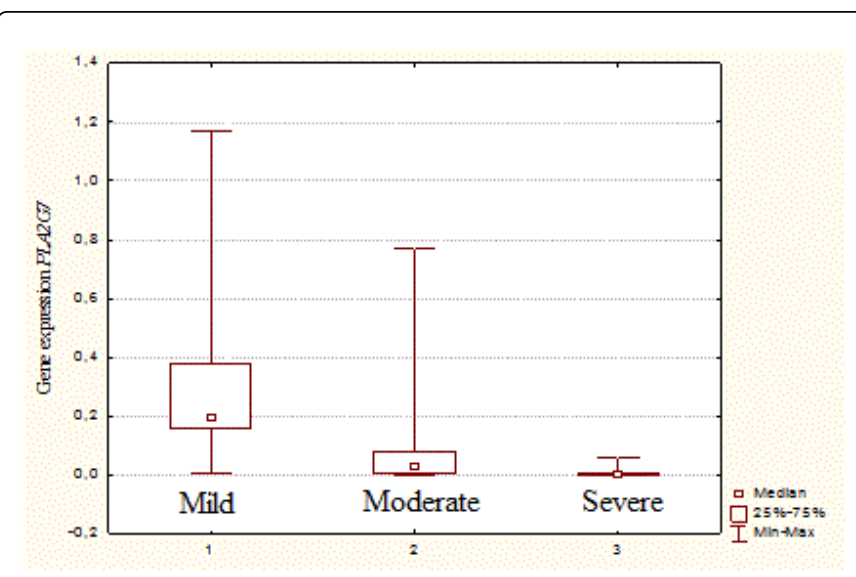

Figure 1: PLA2G7 gene expression in children with a history of mild, moderate and severe food anaphylaxis.

In children with moderate and severe anaphylaxis $(\mathrm{n}=18)$, the transcriptional activity of PLA2G7 gene was more than three times reduced $(\mathrm{Me}=0.005[\mathrm{Q} 1=0.0005 ; \mathrm{Q} 3=0.06])$ in compare with atopic dermatitis children $(\mathrm{p}<0.05)$.

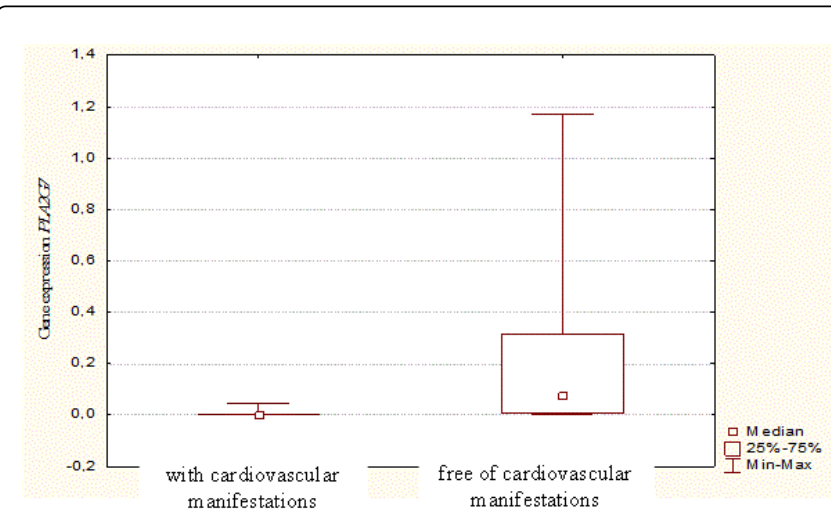

Figure 2: PLA2G7 gene expression in children with cardiovascular manifestations mentioned in anaphylaxis episode.

\section{Discussion}

There are a number of studies devoted to PAF and PAFacetylhydrolase role in anaphylaxis [3,10-12]. Vadas et al. [11] demonstrate blood serum PAF high level and PAF-acetylhydrolase low level correlation with the anaphylaxis severity in patients within the acute phase. Similar results were demonstrated by Pravettoni et al. with the base level of PAF-acetylhydrolase in patients with a history of insect poison anaphylaxis [12]. Inhibition of platelet-activating factor receptor binding was shown to relieve severe symptoms of anaphylaxis in a mouse model [13] and almost completely suppresses anaphylaxis in combination with antihistamines [13]. Enzyme inactivation of PAF in acute phase of anaphylaxis reduced the risk of fatal anaphylaxis in mice due to increase of PAF-acetylhydrolase [14]. PAFacetylhydrolase deficiency increased the risk of severe or fatal anaphylaxis [3].
Since PAF-acetylhydrolase activity is dependent on transcriptional activity of PLA2G7 gene, we assumed PAF-acetylhydrolase low level in the acute phase of anaphylaxis to be determined by decrease of PLA2G7 gene expression. The study was designed to evaluate PLA2G7 mRNA level in patients with a history of anaphylaxis. Significant reduce of PLA2G7 transcriptional activity was demonstrated in children with a history of food anaphylaxis as well as in children with atopic dermatitis in compare with children free of allergy manifestations. These results correspond to some of the previous studies $[3,11,12]$ with certain new points specified in particular to PLA2G7 gene transcriptional activity high level in Ig-E-positive children free of allergy manifestations. We speculate that the increase of PLA2G7 gene expression prevents somehow the development of clinical manifestations related to atopy in these children.

Severe or fatal anaphylaxis in children is known to be associated with asthma [17]. PAF-acetylhydrolase gene Val279Phe mutation through the decrease of corresponding enzyme activity is associated with severe asthma $[18,19]$. PAF-acetylhydrolase gene polymorphism (Ile198Thr; Ala379Val) increases the risk of severe bronchial asthma in Europeans [20]. We demonstrate that asthma was revealed more often in children with severe to moderate anaphylaxis in their history as well. Moderate to severe anaphylaxis children had significantly reduced PLA2G7 gene expression in compare with mild anaphylaxis children, as well as atopic dermatitis children or those free of allergic manifestations. A negative association of anaphylaxis severity and PLA2G7 gene expression level was revealed in our study: gene expression reduced with severity of anaphylaxis. We suggest that low level of PLA2G7 gene transcriptional activity may be considered a biomarker of anaphylaxis severity in children with a history of anaphylaxis.

PAF effects are well-known in anaphylaxis cardiovascular system changes: coronary blood flow reduction, vascular permeability increase, myocardial dysfunction, neutrophils and eosinophils activation and migration within the cardiac tissue $[8,21]$. PAF is supposed to participate in allergic heart attacks and allergic myocardial angina known as Kounis syndrome [22]. Mutations in PAFacetylhydrolase gene are associated with brain stroke, atherosclerosis and myocardial infarction in patients $[23,24]$. PAF is the main factor of disseminated intravascular coagulation (DIC) that may be observed in a fatal anaphylaxis [25]. Our study has revealed the significant reduction in the transcriptional activity of PLA2G7 gene in children with anaphylaxis characterized by clinical symptoms of cardiovascular manifestations in compare with anaphylaxis children free of cardiovascular symptoms.

Alterations of PLA2G7 signal pathways members may influence its transcriptional activity as well. PLA2G7 gene transcriptional activity may be reduced by interferon gamma [26]. This specifies new lines for the PLA2G7 expression reduction research in anaphylaxis.

PLA2G7 gene expression is depended of TLR4, PTAFR and CSF2RA receptors signaling pathways during monocyte to macrophages maturation process [27] (Figure 3). Very-low-densitylipoprotein receptor (VLDLR) also may be involved in the PLA2G7 expression regulation in macrophages [28]. Moreover IFNG decreases PLA2G7 promoter activity by $35 \%$ in macrophages [26]. Alterations in any part of regulation signaling pathways may influence PLA2G7 transcriptional activity. Facts from PLA2G7 gene regulation cascades point out new research prospects for the PLA2G7 level reduction in anaphylaxis. (Figure 3). 
Citation: Esakova NV , Saakyan EK, Kondratieva NS, Kokaeva ZG, Nesterova AP, Golovatenko-Abramov PK, Klimov EA, Treneva MS, Pampura AN (2015) Platelet-Activating Factor-Acetylhydrolase Gene (PLA2G7) Expression in Children with a History of Food Anaphylaxis. J Allergy Ther 6: 211. doi:10.4172/2155-6121.1000211

Page 4 of 5

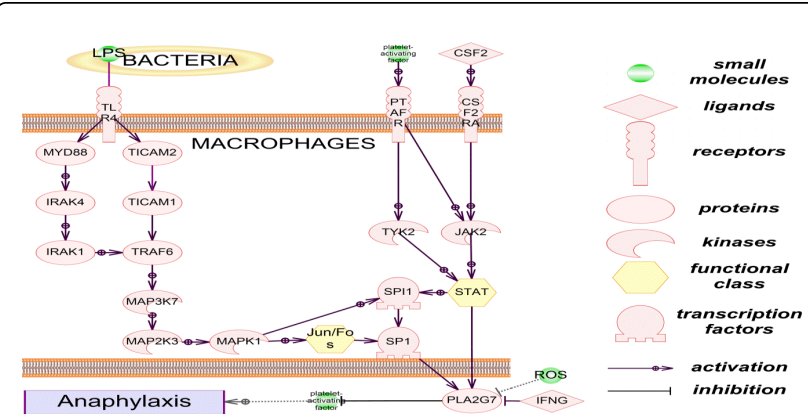

Figure 3: A schematic representation of the PAF acetylhydrolase (PLA2G7) expression regulation. For the reconstruction of the signaling pathway Pathway Studio 10.0 software and ResNet 11 database (Elsevier) were used.

Bacterial lipopolysaccharide (LPS) up-regulates PLA2G7 expression via TLR4 signaling pathway in resident tissue macrophages [29]. Myeloid-specific transcription factors SPI1 and SP1 are involved in PLA2G7 expression in MAPK1-depended manner [30]. PAF may stimulate the expression of its own inactivating enzyme PLA2G7 [29]. Granulocyte macrophage colony-stimulating factor (CSF2) enhances PLA2G7 production by human blood-derived macrophages. [31]. Probably via STAT-related pathway [32]. PLA2G7 gene transcriptional activity is reduced by interferon gamma (IFNG) [30]. Oxygen radicals inactivate PLA2G7 protein activity [33].

Taken together, our study results demonstrate that blood cells PLA2G7 gene mRNA reduction in patients with a history of anaphylaxis could be a biomarker of anaphylaxis severity and define the perspective of PAF blockers efficiency research in this group of patients.

\section{References}

1. Sampson HA, Munoz-Furlong A, Campbell RL, Adkinson NF Jr, Bock SA, et al. (2006) Second symposium on the definition and management of anaphylaxis: summary report-Second National Institute of Allergy and Infectious Disease/Food Allergy and Anaphylaxis Network symposium. J Allergy Clin Immunol 117: 391-397.

2. Kalesnikoff J, Galli SJ (2010) Anaphylaxis: mechanisms of mast cell activation. Chem Immunol Allergy 95: 45-66.

3. Vadas P, Gold M, Perelman B, Liss GM, Lack G, et al. (2008) Plateletactivating factor, PAF acetylhydrolase, and severe anaphylaxis. N Engl J Med 358: 28-35.

4. Finkelman FD (2007) Anaphylaxis: lessons from mouse models. J Allergy Clin Immunol 120: 506-515.

5. Finkelman FD, Rothenberg ME, Brandt EB, Morris SC, Strait RT (2005) Molecular mechanisms of anaphylaxis: lessons from studies with murine models. J Allergy Clin Immunol 115: 449-457.

6. Stafforini DM, McIntyre TM, Zimmerman GA, Prescott SM (2003) Platelet-activating factor, a pleiotrophic mediator of physiological and pathological processes. Crit Rev Clin Lab Sci 40: 643-672.

7. Strait R, Morrist SC, Finkelman FD (2004) Cytokine enhancement of anaphylaxis. Novartis Found Symp 257: 80-91.

8. Montrucchio G, Alloatti G, Camussi G (2000) Role of platelet-activating factor in cardiovascular pathophysiology. Physiol Rev 80: 1669-1699.

9. Strait RT, Morris SC, Yang M, Qu XW, Finkelman FD (2002) Pathways of anaphylaxis in the mouse. J Allergy Clin Immunol 109: 658-668.
10. Vadas P, Gold M, Liss G, Smith C, Yeung J (2003) PAF acetylhydrolase deficiency predisposes to fatal anaphylaxis. J Allergy Clin Immunol 11: S206.

11. Vadas P, Perelman B, Liss G (2013) Platelet-activating factor, histamine, and tryptase levels in human anaphylaxis. J Allergy Clin Immunol 131: 144-149.

12. Pravettoni V, Piantanida M, Primavesi L, Forti S, Pastorello EA (2014) Basal platelet-activating factor acetylhydrolase: Prognostic marker of severe Hymenoptera venom anaphylaxis. J Allergy Clin Immunol 133: 1218-1220.

13. Arias K, Baig M, Colangelo M, Chu D, Walker T, et al. (2009) Concurrent blockade of platelet-activating factor and histamine prevents life-threatening peanut-induced anaphylactic reactions. J Allergy Clin Immunol 124: 307-314.

14. Fukuda Y, Kawashima H, Saito K, Inomata N, Matsui M, et al. (2000) Effect of human plasma-type platelet-activating factor acetylhydrolase in two anaphylactic shock models. Eur J Pharmacol 390: 203-207.

15. Muraro A, Roberts G, Clark A, Eigenmann PA, Halken S, et al. (2007) The management of anaphylaxis in childhood: position paper of the European academy of allergology and clinical immunology. Allergy 62: 857-871.

16. Stalder JF, Barbarot S, Wollenberg A, Holm EA, De Raeve L, et al. (2011) Patient-Oriented SCORAD (PO-SCORAD): a new self-assessment scale in atopic dermatitis validated in Europe. Allergy 66: 1114-1121.

17. Simons FE, Ardusso LR, Bilò MB, El-Gamal YM, Ledford DK, et al. (2011) World Allergy Organization anaphylaxis guidelines: summary. J Allergy Clin Immunol 127: 587-593.

18. Hiramoto M, Yoshida H, Imaizumi T, Yoshimizu N, Satoh K (1998) A mutation in plasma platelet-activating factor acetylhydrolase (Val279$>$ Phe) is a genetic risk factor for stroke. Stroke 28: 2417-2420.

19. Satoh N, Asano K, Naoki K, Fukunaga K, Iwata M, et al. (1999) Plasma platelet-activating factor acetylhydrolase deficiency in Japanese patients with asthma. Am J Respir Crit Care Med 159: 974-979.

20. Kruse S, Mao XQ, Heinzmann A, Blattmann S, Roberts MH, et al. (2000) The Ile198Thr and Ala379Val variants of plasmatic PAF-acetylhydrolase impair catalytical activities and are associated with atopy and asthma. Am J Hum Genet 66: 1522-1530.

21. Braquet P, Touqui L, Shen TY, Vargaftig BB (1987) Perspectives in platelet-activating factor research. Pharmacol Rev 39: 97-145.

22. Kounis NG, Soufras GD, Hahalis G (2013) Anaphylactic Shock: Kounis Hypersensitivity-Associated Syndrome Seems to be the Primary Cause. N Am J Med Sci 5: 631-636.

23. Yamada Y, Yoshida H, Ichihara S, Imaizumi T, Satoh K, et al. (2000) Correlations between plasma platelet-activating factor acetylhydrolase (PAF-AH) activity and PAF-AH genotype, age, and atherosclerosis in a Japanese population. Atherosclerosis 150: 209-216.

24. Yamada Y, Ichihara S, Izawa H, Tanaka M, Yokota M (2001) Association of a G994 --> T (Val279 --> Phe) polymorphism of the plasma plateletactivating factor acetylhydrolase gene with myocardial damage in Japanese patients with nonfamilial hypertrophic cardiomyopathy. J Hum Genet 46: 436-441.

25. Choi IH, Ha TY, Lee DG, Park JS, Lee JH, et al. (1995) Occurrence of disseminated intravascular coagulation (DIC) in active systemic anaphylaxis: role of platelet-activating factor. Clin Exp Immunol 100: 390-394.

26. Cao Y, Stafforini DM, Zimmerman GA, McIntyre TM, Prescott SM (1998) Expression of plasma platelet-activating factor acetylhydrolase is transcriptionally regulated by mediators of inflammation. J Biol Chem 273: 4012-4020.

27. Howard KM (2009) Differential expression of platelet-activating factor acetylhydrolase in lung macrophages. Am J Physiol Lung Cell Mol Physiol 297: L1141-1150.

28. Du Y, Yang M, Wei W, Huynh HD, Herz J, et al. (2012) Macrophage VLDL receptor promotes PAFAH secretion in mother's milk and suppresses systemic inflammation in nursing neonates. Nat Commun 3: 1008. 
Citation: Esakova NV , Saakyan EK, Kondratieva NS, Kokaeva ZG, Nesterova AP, Golovatenko-Abramov PK, Klimov EA, Treneva MS, Pampura AN (2015) Platelet-Activating Factor-Acetylhydrolase Gene (PLA2G7) Expression in Children with a History of Food Anaphylaxis. J Allergy Ther 6: 211. doi:10.4172/2155-6121.1000211

Page 5 of 5

29. Howard KM, Abdel-Al M, Ditmyer M, Patel N (2011) Lipopolysaccharide and platelet-activating factor stimulate expression of platelet-activating factor acetylhydrolase via distinct signaling pathways. Inflamm Res 60: 735-744.

30. Wu X, McIntyre TM, Zimmerman GA, Prescott SM, Stafforini DM (2003) Molecular characterization of the constitutive expression of the plasma platelet-activating factor acetylhydrolase gene in macrophages. Biochem J 375: 351-363.

31. Dupuis F, Denizot Y, Fixe P, Dulery C, Praloran V (1996) PAF and haematopoiesis. X. Macrophage colony-stimulating factor and granulocyte macrophage colony-stimulating factor enhance platelet- activating factor acetylhydrolase production by human blood-derived macrophages. Biochim Biophys Acta 1311: 27-32.

32. Cao Y, Stafforini DM, Zimmerman GA, McIntyre TM, Prescott SM (1998) Expression of plasma platelet-activating factor acetylhydrolase is transcriptionally regulated by mediators of inflammation. J Biol Chem 273: 4012-4020.

33. Heery JM, Kozak M, Stafforini DM, Jones DA, Zimmerman GA, et al. (1995) Oxidatively modified LDL contains phospholipids with plateletactivating factor-like activity and stimulates the growth of smooth muscle cells. J Clin Invest 96: 2322-2330. 